\title{
Notas
}

\section{DETERMINAÇÕES PRELIMINARES DO TEOR DE ÓLEO ESSENCIAL EM CAMOMILA CULTIVADA NO BRASIL (1)}

\author{
MARIO GUILHERME ROBERTO DONALISIO $\left({ }^{2}\right)$
}

\begin{abstract}
RESUMO
Amostras de capítulos florais, pedúnculos florais e caules de camomila cultivada no Brasil foram destiladas em aparelho destilador de Clevenger para avaliação dos respectivos teores de óleo essencial, sendo encontrados os seguintes valores médios por material destilado: capítulos florais: $0,421 \%$; pedúnculos florais: $0,132 \%$ e caules: $0,0251 \%$. Os valores percentuais de óleo essencial relativos a capítulos florais são comparáveis aos encontrados em camomila produzida em diversos países produtores tradicionais: Alemanha: 0,5\%; França: 0,5\%; Hungria: 0,4\%; Áustria: $0,4 \%$; Grécia: $0,4 \%$ e Espanha: $0,3 \%$, e satisfazem as exigências mínimas da farmacopéia brasileira: $0,4 \%$.
\end{abstract}

Termos de indexação: camomila; Matricaria camomilla L.; azuleno.

\section{INTRODUÇÃO}

As flores da camomila (Matricaria camomilla L.) gozam de notada importância pelo seu valor medicinal, com efeitos antiflogísticos, antipiréticos (JANCSO, 1947; GRAHLE, 1956) e antiinflamatórios (WASICKY,

( $\left.{ }^{1}\right)$ Trabalho realizado com a colaboração da Empresa Sanrisil S.A. Recebido para publicação em

28 de şetembro de 1983. pinas (SP). 
1929; BENIGNI, 1971), quando administradas em forma de infusão dos capítulos florais. Esses efeitos medicamentosos são devidos a alguns princípios ativos: azulenos, o chamazuleno principalmente (GUENTHER, 1952; GRAHLE, 1956;BENIGNI, 1971), o bisabolol (GUENTHER, 1952;BENIGNI, 1971; MARTINDALE, 1977) e outros, que compõem o óleo essencial encontrado notadamente nos capítulos florais.

Este trabalho teve por objetivo conhecer a percentagem de óleo essencial contida nos diferentes órgãos de plantas de camomila produzidas comercialmente no Brasil.

\section{MATERIAL E MÉTODOS}

O material estudado foi obtido de lotes comerciais de camomila cultivada no Estado do Paraná e cujas amostras correspondem à produção dos anos 1981/82 e 1982/83.

As amostras foram levadas ao laboratório e submetidas a uma limpe$\mathrm{za}$, com a finalidade de eliminar impurezas grosseiras, constituídas por flores e órgãos de outras espécies vegetais; em seguida, o material foi cuidadosamente separado em: capitulos florais, pedúnculos florais e caules, que foram estudados. Parte da amostra destinou-se à determinação do teor de umidade em estufa a $110^{\circ} \mathrm{C}$ até temperatura constante.

Em cada tipo de material, procedeu-se à extração do óleo essencial por arraste em corrente de vapor em aparelho destilador de laboratório "Clevenger", em balão de $2.000 \mathrm{ml}$, adicionando-se-lhe, no interior do balão, $300 \mathrm{ml}$ de água.

Após montagem do aparelho, acrescentou-se $1 \mathrm{ml}$ de tolueno no interior da coluna de separação, completando-se o nível do sifão com água destilada.

O aquecimento do balão foi feito em manta aquecedora de 500 cal/hora. Iniciada a ebulição, ajustava-se o fluxo de vapor para 2 a $3 \mathrm{ml}$ de condensado por minuto, prolongando-se a destilação por cinco horas.

Terminada a destilação, após o esfriamento espontâneo do balão, coletou-se a fase orgânica azul da coluna de separação em balão volumétrico de $10 \mathrm{ml}$, lavou-se o condensador com mais $3 \mathrm{ml}$ de tolueno, que também era transferido para o balão volumétrico, completando-se o volume e homogeneizando-se a mistura.

Em cápsula de porcelana previamente tarada, colocaram-se $5 \mathrm{ml}$ da mistura contida no balão volumétrico, sendo o solvente evaporado sob vácuo até peso constante. 
A massa de óleo essencial residual, obtida por diferença de pesagem da cápsula de porcelana, permitiu o cálculo da porcentagem de óleo essencial contido no material destilado, cálculo esse que não considerou o teor de umidade das amostras.

\section{RESULTADOS E DISCUSSÃO}

O quadro 1 apresenta o número de amostras analisadas, dados de umidade e teor de óleo essencial encontrados.

QUADRO 1 - Teores de umidade e percentagem de óleo essencial (médias)

\begin{tabular}{|c|c|c|c|c|c|c|c|}
\hline \multirow{2}{*}{ Material } & \multicolumn{3}{|c|}{1982} & \multicolumn{3}{|c|}{1983} & \multirow{2}{*}{ Médias } \\
\hline & Amostras & Umidade & Oleo & Amostras & Umidade & Oleo & \\
\hline & nọ & $\not 8$ & $\%$ & no & $\%$ & $\%$ & \\
\hline $\begin{array}{l}\text { Capítulos } \\
\text { florais }\end{array}$ & 4 & 9,80 & 0,402 & 13 & 10,33 & 0,441 & 0,421 \\
\hline $\begin{array}{l}\text { Pedúnculos } \\
\text { florais }\end{array}$ & 5 & 9,60 & 0,129 & 10 & 9,72 & 0,136 & 0,132 \\
\hline Caules & 4 & 9,30 & 0,019 & 9 & 11,10 & 0,032 & 0,0251 \\
\hline
\end{tabular}

Os pedúnculos florais e os caules contêm baixos teores de óleo essencial, não apresentando valor medicinal.

Mesmo considerando a presença de $5 \%$ de pedúnculos aderentes aos capitulos florais, como admite a Farmacopéia Brasileira (FARMACOPÉIA. . ., 1959), o valor médio de óleo essencial contido nas amostras da camomila brasileira apresentaria $0,407 \%$ de óleo essencial, ainda acima da exigência mínima de $0,4 \%$ (FARMACOPÉIA. . ., 1959).

Os teores de óleo essencial encontrados na camomila brasileira são comparáveis aos da camomila produzida em diversos países produtores 
tradicionais: Alemanha: 0,50\%; França: 0,50\%; Hungria: 0,40\%; Austria: 0,40\%; Grécia: 0,40\% e Espanha: 0,30\% (BENIGNI, 1971; PHARMAZENTISCHEN. . ., 1969).

\section{CONCLUSÃO}

As amostras analisadas, de capítulos florais de camomila cultivada no Brasil, apresentaram teores de óleo essencial superiores a $0,4 \%$, exigência mínima da Farmacopéia Brasileira (FARMACOPÉIA. . ., 1959).

\section{SUMMARY \\ PRELIMINARY DETERMINATION OF ESSENTIAL OIL CONTENT IN CAMOMILE GROWING IN BRASIL}

Trading samples of Matricaria camomilla L. growing in Brazil were analised totally and in their parts (flower, peduncule and stalk) to determine their essencial oil content. The distillation procedure followed the Clevenger method. The average essential oil content of brazilian camomile flowers was $0.421 \%$, which is similar to the oil content of camomile flowers from several other traditional regions, and it is above the minimum level required by the Brazilian Pharmacopoeia $(0.4 \%)$.

Index terms: camomile; Matricaria camomilla L.; azulene.

\section{REFERENCIAS BIBLIGRÁFICAS}

BENIGNI, R.; CAPRA, C. \& CATOTORINI, P.E. Piante medicinali: chimica, farmacologia e terapia. Milano, Messagerie Italiane, 1971.

FARMACOPÉIA brasileira, 1959. v.3, p.177.

GRAHLE, B. Deutsch Apotheker Zeitung, n.93: 538, 1956.

GUENTHER, E. The essential oils. New York, D. Van Nortrand Comp. Inc., 1952. v.5, p. 670 .

JANCSO, M. Histamine as a physiological activator of the Reticulo-Endothelial System. Nature, London, 160(4059): 227-228, 1947.

MARTINDALE. The extra pharmacopoeia. 27.ed. 1977. (mon. 1021)

PHARMAZENTISCHEN Gesellschaft der Deutschen Demokratischen Republik. 1969. p.438-445.

WASICKY, R. Lehrbuch der Physiopharmakognosie. C. Fromme Edit., 1932. p.1929. 